\section{Metabolic syndrome in prostate cancer: impact on risk and outcomes}

\author{
Fatima H Karzai', Ravi A Madan \& William L Dahut*,1
}

\begin{abstract}
Androgen-deprivation therapy (ADT) is a fundamental element of treatment for nonlocalized prostate cancer and for patients with high-risk disease who are not candidates for radical treatment. ADT has been linked to metabolic syndrome, which involves changes in metabolic factors. While distinct from classic metabolic syndrome, this type does include changes in body composition, lipid profiles and insulin resistance. The constellation of risk factors may be associated with cardiovascular morbidity and the onset of diabetes mellitus. Physicians should discuss in detail the risk and benefits of ADT, as well as any needed lifestyle modifications with patients before beginning therapy.
\end{abstract}

First submitted: 3 February 2016; Accepted for publication: 30 March 2016; Published online: 12 April 2016

Metabolic syndrome, a collection of metabolic risk factors for cardiovascular disease and Type II diabetes mellitus, has become more prevalent as obesity has increased worldwide [1]. In 1988, Reaven described resistance to insulin-stimulated glucose uptake, glucose intolerance, hyperinsulinemia, increased very-low-density lipoprotein, triglyceridemia, decreased high-density lipoprotein (HDL) and hypertension, and referred to them collectively as syndrome $\mathrm{X}$ [2]. Currently, these metabolic risk factors associated with insulin resistance are known as metabolic syndrome [3]. Reaven postulated that an underlying cause of cardiovascular disease was insulin resistance that predisposed patients to hypertension, hyperlipidemia and diabetes [2,4]. Classic metabolic syndrome applies where three of the following five criteria are met: fasting plasma glucose level $>110 \mathrm{mg} / \mathrm{dl}$, serum triglyceride level $\geq 150 \mathrm{mg} / \mathrm{dl}$, serum $\mathrm{HDL}<40 \mathrm{mg} / \mathrm{dl}$, waist circumference $>102 \mathrm{~cm}$ and blood pressure $\geq 130 / 85 \mathrm{mmHg}$ (Figure 1) [5]. Aggressive intervention that treats the individual components of this syndrome is recommended for patients with these risk factors [6]. In men with prostate cancer, androgen-deprivation therapy (ADT) results in changes that overlap with metabolic syndrome, including decreased insulin sensitivity, increased triglycerides and increased fat mass [7]. Components of metabolic syndrome may also contribute to the development of prostate cancer [8]. It is imperative that physicians recognize the risk factors that comprise metabolic syndrome in men with prostate cancer and treat them accordingly.

\section{ADT \& metabolic syndrome}

In the USA, prostate cancer is the second leading cause of cancer-related death in males, with an estimated 220,800 new cases and 27,540 deaths in 2015 [9]. In 1941, Huggins and Hodges outlined the benefits of ADT for patients with metastatic prostate cancer [10], for which ADT is an established treatment [11]. Increasingly, ADT with gonadotropin-releasing hormone ( $\mathrm{GnRH})$ agonists and antagonists

'Genitourinary Malignancies Branch, National Cancer Institute, NIH, Bethesda, MD 20892, USA

*Author for correspondence: Tel.: +1 301435 8143; Fax: +1 301435 3854; dahutw@mail.nih.gov

\section{KEYWORDS}

- androgen-deprivation therapy $\bullet$ androgen receptor $\bullet$ cardiovascular risk • diabetes

- gonadotropin-releasing hormone agonist/antagonist

- hypertriglyceridemia

- insulin resistance

- metabolic syndrome

- prostate cancer 


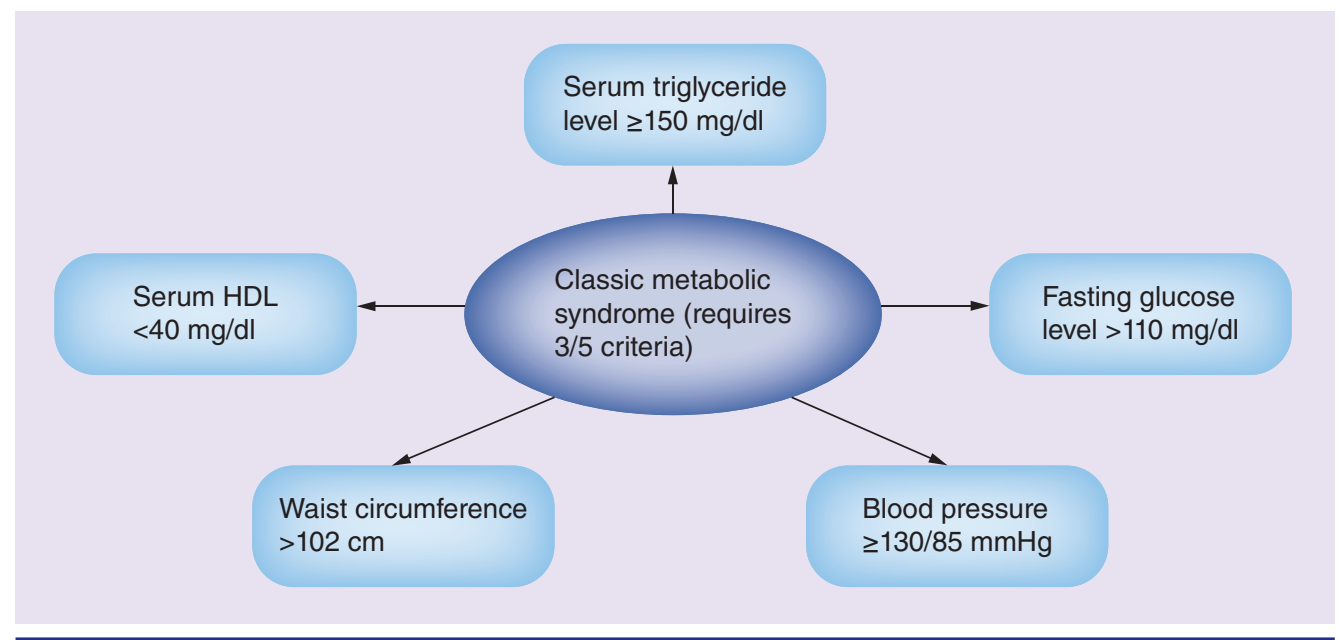

Figure 1. Criteria for the metabolic syndrome.

HDL: High-density lipoprotein.

is used to treat nonmetastatic or recurrent disease after definitive treatment [11,12], and is used along with radiation therapy (RT) to treat high-risk, newly diagnosed disease. Testosterone, a major androgen in males, is synthesized in the testes and released into the blood stream, where it binds to steroid hormone-binding globulin [13]. Androgen promotes the growth of lean mass and suppresses fat deposition $[13,14]$. Low levels of testosterone and steroid hormone-binding globulin may lead to insulin resistance, increased intra-abdominal fat and central obesity [13].

Studies in cancer-free men found that low levels of testosterone may independently promote insulin resistance and metabolic syndrome [15]. A cross-sectional study suggested that men with prostate cancer who are treated with long-term ADT have an increased risk of developing insulin resistance and hyperglycemia [16]. The study included three groups: men with prostate cancer $(n=18)$ who were on ADT for recurrent or metastatic disease for $\geq 12$ months before enrolling on study; age-matched men with nonmetastatic prostate cancer $(\mathrm{n}=17)$ who had radical prostatectomy and/or received RT but no ADT; and age-matched, eugonadal men $(n=18)$ with nonelevated levels of prostate-specific antigen (PSA) [16]. Men in the ADT group had been receiving therapy for 1-9 years and had higher fasting glucose and insulin levels than men in the other two groups $(\mathrm{p}=0.002$ and $\mathrm{p}=0.002$, respectively) [16]. BMI was also significantly higher in the ADT group than in the other two groups $(p=0.005)$. These data suggest that patients who receive long-term ADT may develop adverse metabolic side effects.
Braga-Basaria et al. reported results from a cross-sectional study of 20 men with prostate cancer undergoing ADT for $\geq 12$ months, 18 age-matched men with nonmetastatic prostate cancer who had received local treatment and were found to have increasing PSA, and 20 agematched controls [17]. Men in the ADT group had significantly higher BMI and fasting glucose levels than men in the other two groups. Metabolic syndrome was more prevalent in the ADT group (55\%) than in the non-ADT $(22 \%$; $\mathrm{p}<0.01)$ and control $(20 \% ; \mathrm{p}=0.03)$ groups. The ADT group also had higher triglycerides than the control group. This cross-sectional study demonstrated that ADT is associated with adverse metabolic changes, and that treatment with $\mathrm{GnRH}$ agonists is associated with insulin resistance, lipid alterations and obesity [18].

ADT may also cause changes in body composition, such as increased weight and subcutaneous fat and decreased lean body mass [19]. A prospective study of body composition in men treated with ADT for nonmetastatic prostate cancer randomized 32 patients to receive a 3 -month leuprolide depot $(\mathrm{n}=20)$ or a 3-month leuprolide depot plus pamidronate $(\mathrm{n}=20)$ for 48 weeks [19]. Treatment with the $\mathrm{GnRH}$ agonist led to a $2.4 \%$ increase in weight $(\mathrm{p}=0.005)$, a $9.4 \%$ increase in fat body mass $(\mathrm{p}<0.001)$, and a $2.7 \%$ decrease in lean body mass ( $p<0.001)$ [19]. Another prospective study in men with locally advanced or recurrent nonmetastatic prostate cancer $(n=25)$ assessed the effects of treatment with a short-term GnRH agonist on insulin sensitivity [20]. Patients, none of whom had a history of diabetes mellitus, were evaluated at baseline 
and at 12 weeks. After a fasting period (12 h), patients underwent a 75 -g oral glucose tolerance test in the morning. While the subjects' weight and BMI did not change significantly, fat body mass increased $4.3 \pm 1.3 \%(\mathrm{p}=0.002)$ and lean body mass decreased $1.4 \pm 0.5 \%(\mathrm{p}=0.006)$. Serum total, HDL and LDL cholesterol, as well as triglycerides, all increased, and fasting plasma insulin levels increased $25.9 \pm 9.3 \%$ $(\mathrm{p}=0.04)$. Insulin sensitivity, however, decreased $12.8 \pm 5.9 \%(\mathrm{p}=0.02)$. One patient developed diabetes over the 12-week study period (Table 1). Given the metabolic alterations brought on by ADT, patients should be encouraged to exercise and follow a low-fat, low-carbohydrate diet [21].

\section{Metabolic syndrome \& incidence of prostate cancer}

While metabolic syndrome is a risk factor for men with prostate cancer, lifestyle changes may treat or even prevent this condition and thus alter the course of disease progression [22]. Individual factors of metabolic syndrome have been linked to an increased risk of prostate cancer [23], as demonstrated by a prospective population-based study in Finland [24], where 1880 men with no history of cancer or diabetes mellitus at baseline were followed for an average of 13.2 years. At baseline, 357 men (19\%) had metabolic syndrome based on WHO criteria. Of these men, 183 developed some type of cancer, 56 of which were prostate cancer. In a multivariate analysis, men with metabolic syndrome had a nearly twofold relative risk (RR) of developing prostate cancer. That risk was even higher (RR: 3.00; 95\% CI: $1.22-7.34 ; \mathrm{p}=0.016)$ in men who were overweight or obese (BMI $\geq 27 \mathrm{~kg} / \mathrm{m}^{2}$ ) [24].

In a systematic review and meta-analysis of seven studies, Xiang et al. [25] found that metabolic syndrome was associated with a $36 \%$ increase in odds ratio (OR) of a Gleason score of $\geq 7$ (OR: 1.36 ; 95\% CI: $0.90-2.06$ ) and a $37 \%$ increased risk of advanced clinical stage $(\geq \mathrm{T} 3$; OR: $1.37 ; 95 \%$ CI: $1.12-1.68 ; n=4$ studies). In three studies analyzed, metabolic syndrome was associated with a higher risk of prostate cancerspecific death (RR: 1.12; 95\% CI: 1.02-1.23). Further studies are warranted to determine whether metabolic syndrome is associated with disease progression and advanced clinical stage [25]. It will be important to further evaluate these findings in future prospective trials.

The association between prostate cancer risk and metabolic syndrome was also evaluated in a large clinical trial in men referred for prostate biopsy [26]. The clinical cohort consisted of patients with no prior history of prostate cancer who were undergoing a transrectal ultrasoundguided prostate biopsy. Patients were assessed for metabolic syndrome around the time of biopsy. The study evaluated three outcomes: overall diagnosis of prostate cancer, diagnosis of clinically significant prostate cancer and diagnosis of intermediate- or high-grade prostate cancer (Gleason score: 7-10). Of 2235 men, 494 (22.1\%) had metabolic syndrome. A multivariate analysis found that no single component of metabolic syndrome was significantly associated with a diagnosis of prostate cancer. However, an increasing number of metabolic syndrome components were associated with higher prostate cancer grade $(p<0.001)$ [26]. Having $\geq$ three components of metabolic syndrome was associated with a higher risk of prostate cancer (OR: 1.54; 95\% CI: 1.17-2.04; $\mathrm{p}=0.002)$, castrate-sensitive prostate cancer (OR: 1.56; 95\% CI: 1.17-2.08; $\mathrm{p}=0.002)$ and intermediate- to high-grade prostate cancer (OR: $1.56 ; 95 \%$ CI: 1.16-2.10; $\mathrm{p}=$ $0.003)$ [26]. This observational study highlighted the need for further studies to evaluate the association between prostate cancer incidence and aggressiveness, and metabolic syndrome.

\begin{tabular}{|c|c|c|c|}
\hline Study (year) & Study type & Summary of findings & Ref. \\
\hline $\begin{array}{l}\text { Basaria et al. } \\
(2006)\end{array}$ & $\begin{array}{l}\text { Cross-sectional } \\
\text { study }\end{array}$ & $\begin{array}{l}\text { Long-term ADT may increase risk of developing insulin resistance } \\
\text { and hyperglycemia in men with prostate cancer }\end{array}$ & [16] \\
\hline $\begin{array}{l}\text { Braga-Basaria } \\
\text { et al. (2006) }\end{array}$ & $\begin{array}{l}\text { Cross-sectional } \\
\text { study }\end{array}$ & $\begin{array}{l}\text { Long-term ADT is associated with insulin resistance, lipid } \\
\text { alterations and abdominal obesity }\end{array}$ & {$[17]$} \\
\hline $\begin{array}{l}\text { Smith et al. } \\
(2002)\end{array}$ & $\begin{array}{l}\text { Prospective } \\
\text { study }\end{array}$ & $\begin{array}{l}\text { Treatment with ADT can lead to increase in weight, fat body } \\
\text { mass and decrease in lean body mass in men with nonmetastatic } \\
\text { prostate cancer }\end{array}$ & [19] \\
\hline $\begin{array}{l}\text { Smith et al. } \\
\text { (2006) }\end{array}$ & $\begin{array}{l}\text { Prospective } \\
\text { study }\end{array}$ & $\begin{array}{l}\text { Insulin sensitivity decreased with short-term ADT in men with } \\
\text { locally advanced or recurrent metastatic prostate cancer }\end{array}$ & [20] \\
\hline
\end{tabular}




\section{ADT \& cardiovascular risk factors}

Although a definitive link between cardiovascular disease and ADT has not been established, it is known that ADT decreases insulin sensitivity, increases serum triglycerides and increases fat [27], thereby increasing cardiovascular risk factors. From 1992 to 1999, Keating et al. conducted a study to evaluate the potential association between ADT and cardiovascular disease. They enrolled 73,196 men aged $\geq 66$ years who had nonmetastatic prostate cancer [28] and observed them until 2001. In all, 36.3\% of patients received a $\mathrm{GnRH}$ agonist, while $6.9 \%$ underwent bilateral orchiectomy [13]. GnRH agonist was associated with an increased risk of coronary heart disease (adjusted hazard ratio [HR]: 1.16; $\mathrm{p}<0.001)$, myocardial infarction (MI; HR: $1.11 ; \mathrm{p}=0.3$ ) and sudden cardiac death (HR: 1.16; $\mathrm{p}=0.004)$. The increased risk of coronary heart disease was associated with as few as $1-4$ months of treatment with a GnRH agonist [28].

D'Amico et al. studied whether ADT affected time to fatal MI [29]. In three trials conducted between February 1995 and June 2001, 1372 patients were randomized to receive RT plus 0 versus 3 versus 6,3 versus 8 or 0 versus 6 months of ADT [29]. Men who were $\geq 65$ years old and who had been randomized to receive 6 months of ADT had less time to fatal MI compared with men who received no ADT. Further studies are needed to establish an association between duration of ADT and time to fatal MI.

Other studies in locally advanced prostate cancer, such as the Phase III Radiation Therapy Oncology Group (RTOG) 92-02 trial, found no evidence that longer-term adjuvant ADT with a GnRH agonist increased cardiovascular mortality compared with short-term ADT [30]. In this multicenter, prospective, randomized controlled trial, men with locally advanced disease (T2c-T4, PSA $<150 \mathrm{ng} / \mathrm{ml}$ ) received RT with 4 months of the GnRH agonist goserelin, and then were randomized to no additional therapy or 24 months of adjuvant goserelin [30]. Cancer-specific mortality declined with longerterm therapy. Of 765 deaths, 185 (24.2\%) were categorized as cardiovascular-associated. Differences in the 5-year cardiovascular mortality rate were not statistically significant between men who received longer-term ADT and those who received short-term ADT (5.9 vs 4.8\%; $\mathrm{p}=0.16)$. In the Phase III RTOG 85-31 trial, patients with locally advanced prostate cancer were randomized to receive adjuvant goserelin with RT $(\mathrm{n}=477)$ or RT alone $(\mathrm{n}=468)$ [31]. Of 574 deaths, 117 (20.4\%) were deemed to be cardiovascular-associated. The 9-year cardiovascular mortality rate for men receiving adjuvant goserelin was 8.4 versus $11.4 \%$ for men treated with RT alone $(p=0.17)$. Multiple regression analyses found no significant association between treatment with a GnRH agonist and risk of cardiovascular death [31].

In a review and meta-analysis of eight prospective randomized Phase III trials, Nguyen et al. compared immediate GnRH agonist-based ADT versus no or deferred ADT in men $(n=4141)$ with nonmetastatic, unfavorable-risk prostate cancer to see if there was an association between ADT and cardiovascular mortality, prostate cancer-specific mortality and all-cause mortality [32]. Median follow-up was 7.6-13.2 years. Investigators found no evidence that ADT increases cardiovascular mortality. In the ADT group, the overall incidence of cardiovascular death was $11.0 \%$ (95\% CI: 8.3-14.5\%) versus $11.2 \%$ (95\% CI: $8.3-15.0 \%$ ) in the non-ADT group. Furthermore, ADT was associated with improved prostate cancer-specific mortality and overall survival (OS). A subgroup analysis showed no increased risk of cardiovascular death in men treated with ADT for $\leq 6$ months or $\geq 3$ years, in men who received RT, or where the median age at study enrollment was $\geq 70$ years (Table 2).

Nguyen $e t$ al. also retrospectively evaluated men with cT1c-T3aN0M0 prostate cancer treated with low-dose brachytherapy from 1991 through 2006 to ascertain if treatment with ADT negatively affects $O S$ in men with congestive heart failure (CHF) or a history of MI [33]. The study cohort consisted of 14,594 men, $1378(9.4 \%)$ of whom had a history of CHF or MI. A median of 4 months of neoadjuvant ADT was given to $42.9 \%$ of the cohort, while $22.6 \%$ received supplemental RT. Patients were stratified into three groups: low-, intermediate- or high-risk, based on the National Comprehensive Cancer Network's classification [33]. Patients in the intermediateand high-risk groups received ADT more frequently than those in the low-risk group (low risk: $33.7 \%$; intermediate risk: $44.06 \%$; high risk: $69.5 \%$ ). Men with CHF or a history of MI had an increase in all-cause mortality (ACM) with ADT (adjusted HR: 1.76; 95\% CI: 1.32-2.34; $\mathrm{p}=0.0001$ ), with 5-year estimates of ACM of $22.71 \%$ with ADT and $11.62 \%$ without ADT (p log-rank < 0.0001) [33]. An increase in ACM 


\begin{tabular}{|c|c|c|c|}
\hline Study (year) & Study type & Summary of findings & Ref. \\
\hline $\begin{array}{l}\text { Keating et al. } \\
\text { (2006) }\end{array}$ & $\begin{array}{l}\text { Observational study of a } \\
\text { population-based cohort }\end{array}$ & $\begin{array}{l}\text { Treatment with ADT in men with locoregional } \\
\text { prostate cancer may be associated with an increased } \\
\text { risk of cardiovascular disease }\end{array}$ & [28] \\
\hline $\begin{array}{l}\text { D'Amico } \\
\text { et al. }(2007)\end{array}$ & $\begin{array}{l}\text { Pooled data analysis of } \\
\text { three randomized trials }\end{array}$ & $\begin{array}{l}\text { Men, aged } 65 \text { years old, randomly assigned to receive } \\
6 \text { months of ADT vs no ADT had shorter times to } \\
\text { fatal MI }\end{array}$ & [29] \\
\hline $\begin{array}{l}\text { Efstathiou } \\
\text { et al. (2008) }\end{array}$ & $\begin{array}{l}\text { Phase III RTOG 92-02 study, } \\
\text { prospective, randomized } \\
\text { controlled trial }\end{array}$ & $\begin{array}{l}\text { 5-year CV mortality rate was not statistically } \\
\text { significant between men who received longer term vs } \\
\text { short-term ADT in locally advanced prostate cancer }\end{array}$ & [30] \\
\hline $\begin{array}{l}\text { Nguyen et al. } \\
\text { (2011) }\end{array}$ & $\begin{array}{l}\text { Meta-analysis of eight } \\
\text { prospective randomized } \\
\text { Phase II trials }\end{array}$ & $\begin{array}{l}\text { Comparison between immediate ADT vs no or } \\
\text { deferred ADT in men with nonmetastatic unfavorable } \\
\text { risk prostate cancer found no evidence ADT increases } \\
\text { CV mortality }\end{array}$ & [32] \\
\hline \multicolumn{4}{|c|}{ ADT: Androgen-deprivation therapy; CV: Cardiovascular; MI: Myocardial infarction. } \\
\hline
\end{tabular}

was seen in all risk groups [33]. However, there were no data on the severity of patients' CHF or MI or on the causes of death for all patients, and data on the timing of salvage ADT were incomplete. Clearly, in patients with a history of $\mathrm{CHF}$ or MI, ADT should be initiated cautiously.

While studies have confirmed that ADT affects cardiovascular risk factors, studies on ADT and the risk of cardiovascular mortality have had conflicting results. An advisory panel consisting of members of the American Heart Association, the American Cancer Society, and the American Urological Association (endorsed by the American Society for Radiation Oncology) was commissioned to evaluate a possible relationship between ADT and cardiovascular events in patients with prostate cancer [34]. This panel found a possible association between ADT and cardiovascular risk and outlined the following recommendations: Patients for whom ADT is necessary are advised to follow-up with their primary care physicians within the first 3-6 months of starting ADT and periodically thereafter to evaluate blood pressure, lipid profile and glucose level; with long-term ADT, lipid profile and blood glucose should be checked yearly; patients do not need to be referred to cardiology, endocrinology or primary care before ADT is started; at present, specific cardiac testing or procedures are not indicated for patients with cardiovascular disease who are scheduled to begin ADT.

\section{ADT \& survival}

Regardless of any association with cardiovascular risk, ADT does improve OS in men with high-risk prostate cancer. A Phase III trial in men $<80$ years of age who had T1-T2 prostate adenocarcinoma randomized patients to RT $(\mathrm{n}=208)$ or RT plus immediate ADT $(n=207)$ [35]. Patients received goserelin every month starting the first day of RT to the pelvis and for 3 years thereafter. Clinical disease-free survival was greater in the combination treatment group, with $47 \%$ disease-free at 10 years versus $22.7 \%$ disease-free in the RT-only group (HR: 0.42; 95\% CI: 0.33-0.55; p < 0.0001) [35]. The 10-year OS rate in the RT-plus-immediateADT arm was 58.1\% (95\% CI: 49.2-66.0) versus $39.8 \%$ in the RT-only group (95\% CI: 31.9-47.5). Patients with T3-T4 prostate cancer who received combination treatment also had a greater OS benefit (58.5 vs 37.7\%; HR: 0.56; 95\% CI: 0.41-0.75; p = 0.0001). Furthermore, the 10-year cumulative incidence of prostate-cancer mortality declined, while locoregional control and distant-metastasis-free survival improved in the combination-treatment arm. Notably, the two treatment arms showed no significant difference in cardiovascular mortality, regardless of whether or not patients had cardiovascular disease at study enrollment. In this study, the combination of RT plus 3 years of ADT led to improved OS without significantly increasing cardiovascular mortality in men with high-risk prostate cancer.

In a study by Messing et al., beginning ADT immediately post-radical prostatectomy and pelvic lymphadenectomy improved survival in men with node-positive prostate cancer and reduced the risk of recurrence [36]. Patients with localized disease, all of whom had undergone radical prostatectomy and bilateral pelvic lymphadenectomy, were randomized to receive immediate goserelin $3.6 \mathrm{mg}$ subcutaneously every 28 days) or bilateral orchiectomy, or observed for signs of progression other 
than rising or newly detectable PSA. A median follow-up of 7.1 years showed that OS significantly improved among men $(n=47)$ receiving immediate therapy versus men $(n=51)$ observed for signs of progression $(\mathrm{p}=0.02)$. At a median followup of 11.9 years, OS in the immediate-treatment group significantly improved (HR: $1.84 ; 95 \% \mathrm{CI}$ : $1.01-3.35 ; \mathrm{p}=0.04)$ compared with the delayedtreatment group [37]. Significant improvements were also seen in prostate cancer-specific survival and progression-free survival [37].

Nabid et al. have presented preliminary data from a randomized study evaluating the optimal duration of ADT in high-risk prostate cancer patients. Patients in arm one $(\mathrm{n}=310)$ received pelvic RT and 36 months of goserelin $(10.8 \mathrm{mg}$ every 3 months); patients in arm two $(\mathrm{n}=320)$ received pelvic RT and 18 months of goserelin [38]. The median follow-up was 6.5 years. In arm one, the 10-year OS rate was 61.9 versus $58.6 \%$ for arm two $(\mathrm{p}=0.275)$. The diseasespecific survival rate was $84.1 \%$ in arm one versus $83.7 \%$ in arm two $(\mathrm{p}=0.819)$. Most patients had high-risk prostate cancer (T2-T3). These results show that 18 months of ADT in combination with RT is comparable to 36 months of ADT, and may represent an option for high-risk patients with comorbidities that make treatment with long-term ADT problematic.

The standard of care for patients with prostate cancer with a high risk of metastasis is RT with 3 years of ADT. Prospective studies are needed to identify patient populations that would receive the most benefit from $\mathrm{ADT}$ and to identify optimal duration of treatment without the development of metabolic syndrome.

\section{Androgen receptor $\&$ androgen biosynthesis}

Two landmark studies in 2004 showed an OS benefit in metastatic castration-resistant prostate cancer (mCRPC) with docetaxel plus prednisone [39,40]. Unfortunately, for men whose metastatic prostate cancer has progressed on ADT despite castration levels of testosterone, this combination is not curative [41], making it necessary to explore alternative treatments such as targeting the androgen receptor (AR) and sustained androgen signaling. CRPC is driven by both overexpression of the AR and continuous androgen signaling $[42,43]$. Enzalutamide, a potent oral antiandrogen, prevents translocation of the AR to the nucleus and inhibits AR binding to chromosomal DNA at the level of the nucleus [44]. The AFFIRM trial, a randomized, double-blind Phase III trial, evaluated enzalutamide versus placebo in patients with mCRPC previously treated with chemotherapy [45]. Patients were randomized to receive enzalutamide $(n=800)$ or placebo $(n=399)$. The primary end point of OS improved significantly in the enzalutamide group (18.4 vs 13.6 months in the placebo group), and this survival advantage was seen in all patient subgroups. Prechemotherapy enzalutamide has also been studied in men with asymptomatic or minimally symptomatic mCRPC. In the Phase III randomized, double-blind, placebo-controlled PREVAIL study, 1715 chemotherapy-naive men with mCRPC were treated with enzalutamide $160 \mathrm{mg} /$ day or placebo [46]. An interim analysis showed an estimated median OS of 32.4 months in the enzalutamide arm (95\% CI: 31.5-upper limit not yet reached) versus 30.2 months in the placebo arm (95\% CI: 28-upper limit not yet reached).

While enzalutamide has shown an OS benefit both pre- and post-chemotherapy in $\mathrm{mCRPC}$, it is important to identify any metabolic effects it may have. Although the AFFRIM trial was not designed to evaluate for metabolic syndrome, there were no significant differences in rates of hyperglycemia, hyperlipidemia, glucose intolerance or weight gain between patients in the enzalutamide and placebo groups [45]. Interim results were recently presented from an ongoing Phase II study evaluating enzalutamide monotherapy $(160 \mathrm{mg} / \mathrm{day}$ for 25 weeks $)$ in men with any stage of hormone-naive prostate cancer requiring hormonal therapy. Patients had noncastrate levels of testosterone ( $\geq 230 \mathrm{ng} / \mathrm{dl})$. End points included metabolic changes in body composition, bone biomarkers, lipids and glycemic profiles [47]. In the 67 patients enrolled, metabolic variables were not substantially affected (mean change in fat body mass: $6.9 \%$; total cholesterol: 4.6\%; triglycerides: $6.5 \%$; HgbA1C: $-2.0 \%$; fasting glucose: $-0.1 \%$ ).

Abiraterone acetate is another drug that inhibits androgen production by blocking CYP17 lyase, thereby blocking the synthesis of adrenal and testicular androgens and inhibiting androgen production by tumor cells $[48,49]$. In a randomized, double-blind, placebo-controlled Phase III study, 1195 patients with mCRPC who had previously been treated with docetaxel received abiraterone plus prednisone $(\mathrm{n}=$ 797) or placebo plus prednisone $(\mathrm{n}=398)$ [49]. 
OS improved in the abiraterone arm (14.8 vs 10.9 months in the placebo arm; HR: 0.65; 95\% CI: 0.54-0.77; p < 0.001). There was a slightly higher but statistically insignificant rate of cardiac events in the abiraterone arm versus the placebo arm ( 13 vs $11 \%$, respectively; $\mathrm{p}=0.14$ ), and fatal cardiac events did not significantly increase in the abiraterone group versus the placebo group (1.1 vs $1.3 \%$, respectively) [49]. Abiraterone has also been approved for patients with mCRPC prechemotherapy. Ryan et al. reported the results of a double-blind, placebo-controlled study that randomized patients $1: 1$ to receive abiraterone plus prednisone $(n=546)$ or placebo plus prednisone $(n=542)$ [50]. The abiraterone group showed a trend toward improved OS (median not reached vs 27.2 months for placebo plus prednisone; HR: 0.75; 95\% CI: 0.61-0.93; p = 0.01 ) and prolonged radiographic progressionfree survival (median time to event 16.5 vs 8.3 months; HR: 0.53). Grade 1-4 adverse cardiac events were reported in $19 \%$ of patients in the abiraterone group versus $16 \%$ in the placebo plus prednisone group. These trials show androgen biosynthesis to be an integral component of treatment for prostate cancer. The development of more potent AR-targeting drugs and inhibitors of testosterone biosynthesis makes it imperative to closely monitor patients for symptoms of metabolic syndrome.

Estrogen-related pathways also play an important role in the development and progression of prostate cancer [51]. In recent years, we have come to better understand the function of AR in CRPC and the cross-talk between AR and estrogen receptor $\alpha$ (ERA) [51,52]. In prostate cancer, increased ERA signaling, in association with $A R$ signaling, can lead to disease progression [53]. Estrogens, acting on both ERA and estrogen receptor $\beta$, regulate metabolic homeostasis and lipid metabolism. ERA mediates the beneficial effects of estrogens, including antilipogenesis and reduction of bodyweight/fat mass [54], and has a protective role in insulin and glucose metabolism [51]. Further studies are needed to evaluate the use of ERA antagonists in conjunction with ADT to treat prostate cancer [53].

\section{Conclusion}

Since the 1940s, testosterone blockade has been a fundamental aspect of treatment for prostate cancer, chiefly in the metastatic setting. However, ADT results in a constellation of metabolic alterations that need close monitoring and intervention when necessary. Because these metabolic changes may increase the risk of insulin insensitivity and/or cardiovascular death, it is imperative to weigh the potential risks and benefits of ADT, particularly for patients with locoregional and/or high-risk disease, where ADT has been shown to improve OS.

\section{Future perspective}

Future studies must elucidate the association between ADT and metabolic syndrome, especially in regard to cardiovascular morbidity and mortality and diabetes mellitus. These studies must also identify patient populations most likely to experience high rates of complications with ADT, as well as optimal duration of treatment for specific patient populations. Finally, physicians must be able to recognize morbidities associated with ADT-induced metabolic syndrome and take steps to prevent them.

\section{EXECUTIVE SUMMARY}

- Changes in metabolic factors have been linked to treatment with androgen-deprivation therapy (ADT). ADT may alter body composition, insulin resistance and lipids. Modifications in diet and exercise should be discussed with patients on ADT.

- Components of metabolic syndrome may contribute to prostate cancer development or progression. Prospective studies must further evaluate these findings.

- ADT affects cardiovascular risk factors. An advisory panel recommends referral to a primary care physician for periodic evaluation while on ADT. Specific cardiac testing is not indicated.

- ADT improves overall survival in men with high-risk prostate cancer. Standard of care for men with high-risk prostate cancer is radiation therapy with ADT. Prospective studies are needed to determine optimal duration of therapy with ADT for differing patient populations.

- Drugs targeting the androgen receptor inhibit testosterone biosynthesis. Patients treated with drugs such as enzalutamide or abiraterone must be monitored for symptoms of metabolic syndrome. 
Author contributions

All authors contributed equally to this paper.

Financial \& competing interests disclosure

The authors have no relevant affliations or financial involve-

ment with any organization or entity with a financial interest in or financial conflict with the subject matter or materials discussed in the manuscript. This includes employment, consultancies, honoraria, stock ownership or options, expert testimony, grants or patents received or pending, or royalties.

No writing assistance was utilized in the production of this manuscript.

\section{References}

Papers of special note have been highlighted as: - of interest; $\bullet$ of considerable interest

1 Eckel RH, Grundy SM, Zimmet PZ. The metabolic syndrome. Lancet 365, 1415-1428 (2005).

2 Reaven GM. Banting lecture 1988. Role of insulin resistance in human disease. Diabetes 37, 1595-1607 (1988).

- Introduced a constellation of abnormalities, including insulin resistance, known as syndrome $\mathrm{X}$ to the medical community in 1988. Syndrome $X$ later became known as metabolic syndrome.

3 Third Report of the National Cholesterol Education Program (NCEP) Expert Panel on Detection, Evaluation, and Treatment of High Blood Cholesterol in Adults (Adult Treatment Panel III) final report. Circulation 106, 3143-3421 (2002).

4 Kahn R, Buse J, Ferrannini E, Stern M. The metabolic syndrome: time for a critical appraisal. Joint statement from the American Diabetes Association and the European Association for the Study of Diabetes. Diabetologia 48, 1684-1699 (2005).

5 Executive Summary of The Third Report of The National Cholesterol Education Program (NCEP) Expert Panel on Detection, Evaluation, and Treatment of High Blood Cholesterol in Adults (Adult Treatment Panel III). JAMA 285, 2486-2497 (2001).

6 Gallagher EJ, Leroith D, Karnieli E. The metabolic syndrome - from insulin resistance to obesity and diabetes. Med. Clin. North Am. 95, 855-873 (2011).

7 Smith MR, Lee H, McGovern F et al. Metabolic changes during gonadotropinreleasing hormone agonist therapy for prostate cancer: differences from the classic metabolic syndrome. Cancer 112, 2188-2194 (2008).

8 McGrowder DA, Jackson LA, Crawford TV. Prostate cancer and metabolic syndrome: is there a link? Asian Pac. J. Cancer Prev. 13, 1-13 (2012).

9 Siegel RL, Miller KD, Jemal A. Cancer statistics, 2015. CA Cancer J. Clin. 65, 5-29 (2015).
10 Huggins C, Hodges CV. Studies on prostatic cancer: I. The effect of castration, of estrogen and of androgen injection on serum phosphatases in metastatic carcinoma of the prostate. 1941. J. Urol. 168, 9-12 (2002).

- This pioneering work established a definitive relationship between hormones and prostate cancer, and hormonal therapy as a mainstay of treatment.

11 Roach M 3rd. Current trends for the use of androgen deprivation therapy in conjunction with radiotherapy for patients with unfavorable intermediate-risk, high-risk, localized, and locally advanced prostate cancer. Cancer 120, 1620-1629 (2014).

12 Bastian PJ, Boorjian SA, Bossi A et al. High-risk prostate cancer: from definition to contemporary management. Eur. Urol. 61, 1096-1106 (2012).

13 Yu IC, Lin HY, Sparks JD, Yeh S, Chang C. Androgen receptor roles in insulin resistance and obesity in males: the linkage of androgendeprivation therapy to metabolic syndrome. Diabetes 63, 3180-3188 (2014).

14 Vermeulen A, Goemaere S, Kaufman JM. Testosterone, body composition and aging. J. Endocrinol. Invest. 22, 110-116 (1999).

15 Laaksonen DE, Niskanen L, Punnonen K et al. Testosterone and sex hormone-binding globulin predict the metabolic syndrome and diabetes in middle-aged men. Diabetes Care 27, 1036-1041 (2004).

16 Basaria S, Muller DC, Carducci MA, Egan J, Dobs AS. Hyperglycemia and insulin resistance in men with prostate carcinoma who receive androgen-deprivation therapy. Cancer 106, 581-588 (2006).

17 Braga-Basaria M, Dobs AS, Muller DC et al. Metabolic syndrome in men with prostate cancer undergoing long-term androgendeprivation therapy. J. Clin. Oncol. 24, 3979-3983 (2006).

18 Saylor PJ, Smith MR. Metabolic complications of androgen deprivation therapy for prostate cancer. J. Urol. 189, S34-S42; discussion S43-S34 (2013).

19 Smith MR, Finkelstein JS, McGovern FJ et al. Changes in body composition during androgen deprivation therapy for prostate cancer. J. Clin. Endocrinol. Metab. 87, 599-603 (2002).

20 Smith MR, Lee H, Nathan DM. Insulin sensitivity during combined androgen blockade for prostate cancer. J. Clin. Endocrinol. Metab. 91, 1305-1308 (2006).

21 Liu Y, Hu F, Li D et al. Does physical activity reduce the risk of prostate cancer? A systematic review and meta-analysis. Eur. Urol. 60, 1029-1044 (2011).

22 Conteduca V, Di Lorenzo G, Bozza G, Ardito R, Aieta M. Metabolic syndrome as a peculiar target for management of prostate cancer patients. Clin. Genitourin. Cancer 11, 211-220 (2013).

23 Wolk A, Mantzoros CS, Andersson SO et al. Insulin-like growth factor 1 and prostate cancer risk: a population-based, case-control study. J. Natl Cancer Inst. 90, 911-915 (1998).

24 Laukkanen JA, Laaksonen DE, Niskanen L, Pukkala E, Hakkarainen A, Salonen JT. Metabolic syndrome and the risk of prostate cancer in Finnish men: a population-based study. Cancer Epidemiol. Biomarkers Prev. 13, 1646-1650 (2004).

25 Xiang YZ, Xiong H, Cui ZL et al. The association between metabolic syndrome and the risk of prostate cancer, high-grade prostate cancer, advanced prostate cancer, prostate cancer-specific mortality and biochemical recurrence. J. Exp. Clin. Cancer Res. 32, 9 (2013).

26 Bhindi B, Locke J, Alibhai SM et al. Dissecting the association between metabolic syndrome and prostate cancer risk: analysis of a large clinical cohort. Eur. Urol. 67, 64-70 (2015).

27 Smith MR, Lee H, Fallon MA, Nathan DM. Adipocytokines, obesity, and insulin resistance during combined androgen blockade for prostate cancer. Urology 71 , 318-322 (2008).

28 Keating NL, O'Malley AJ, Smith MR. Diabetes and cardiovascular disease during androgen deprivation therapy for prostate cancer. J. Clin. Oncol. 24, 4448-4456 (2006).

29 D'Amico AV, Denham JW, Crook J et al. Influence of androgen suppression therapy for 
prostate cancer on the frequency and timing of fatal myocardial infarctions. J. Clin. Oncol. 25, 2420-2425 (2007).

30 Efstathiou JA, Bae K, Shipley WU et al. Cardiovascular mortality and duration of androgen deprivation for locally advanced prostate cancer: analysis of RTOG 92-02. Eur. Urol. 54, 816-823 (2008).

31 Efstathiou JA, Bae K, Shipley WU et al. Cardiovascular mortality after androgen deprivation therapy for locally advanced prostate cancer: RTOG 85-31. J. Clin. Oncol. 27, 92-99 (2009).

32 Nguyen PL, Je Y, Schutz FA et al. Association of androgen deprivation therapy with cardiovascular death in patients with prostate cancer: a meta-analysis of randomized trials. JAMA 306, 2359-2366 (2011).

33 Nguyen PL, Chen MH, Beckman JA et al. Influence of androgen deprivation therapy on all-cause mortality in men with high-risk prostate cancer and a history of congestive heart failure or myocardial infarction. Int. J. Radiat. Oncol. Biol. Phys. 82, 1411-1416 (2012).

34 Levine GN, D'Amico AV, Berger P et al. Androgen-deprivation therapy in prostate cancer and cardiovascular risk: a science advisory from the American Heart Association, American Cancer Society, and American Urological Association: endorsed by the American Society for Radiation Oncology. CA Cancer J. Clin. 60, 194-201 (2010).

35 Bolla M, Van Tienhoven G, Warde P et al. External irradiation with or without long-term androgen suppression for prostate cancer with high metastatic risk: 10 year results of an EORTC randomised study. Lancet Oncol. 11, 1066-1073 (2010).

- This Phase III trial reported improvement in 10 -year disease-free and overall survival in patients with high-risk prostate cancer treated with immediate androgen suppression during and for 3 years after external radiation therapy.

36 Messing EM, Manola J, Sarosdy M, Wilding G, Crawford ED, Trump D. Immediate hormonal therapy compared with observation after radical prostatectomy and pelvic lymphadenectomy in men with node-positive prostate cancer. N. Engl. J. Med. 341, 1781-1788 (1999).

- Established benefit in progression-free survival and overall survival in men with node-positive prostate cancer treated with immediate androgen-deprivation therapy after radical prostatectomy and pelvic lymphadenectomy.

37 Messing EM, Manola J, Yao J et al. Immediate versus deferred androgen deprivation treatment in patients with node-positive prostate cancer after radical prostatectomy and pelvic lymphadenectomy. Lancet Oncol. 7, 472-479 (2006).

38 Nabid A, Carrier N, Martin A et al. Duration of androgen deprivation therapy in high-risk prostate cancer: a randomized trial. J. Clin. Oncol. 31(Suppl.), Abstract LBA4510 (2013).

39 Petrylak DP, Tangen CM, Hussain MH et al. Docetaxel and estramustine compared with mitoxantrone and prednisone for advanced refractory prostate cancer. $N$. Engl. J. Med. 351, 1513-1520 (2004).

-• This landmark Phase III trial revealed an overall survival benefit with docetaxel given every 3 weeks with estramustine and prednisone compared with mitoxantrone and prednisone in metastatic castration-resistant prostate cancer.

40 Tannock IF, de Wit R, Berry WR et al. Docetaxel plus prednisone or mitoxantrone plus prednisone for advanced prostate cancer. N. Engl. J. Med. 351, 1502-1512 (2004).

-• This landmark Phase III trial revealed an overall survival benefit with docetaxel given every 3 weeks with prednisone compared with mitoxantrone and prednisone in metastatic castration-resistant prostate cancer.

41 Scher HI, Sawyers CL. Biology of progressive, castration-resistant prostate cancer: directed therapies targeting the androgen-receptor signaling axis. J. Clin. Oncol. 23, 8253-8261 (2005).

42 Chen CD, Welsbie DS, Tran C et al. Molecular determinants of resistance to antiandrogen therapy. Nat. Med. 10, 33-39 (2004).

43 Sharifi N. Steroid receptors aplenty in prostate cancer. N. Engl. J. Med. 370, 970-971 (2014).
44 Saad F. Evidence for the efficacy of enzalutamide in postchemotherapy metastatic castrate-resistant prostate cancer. Ther. $A d v$. Urol. 5, 201-210 (2013).

45 Scher HI, Fizazi K, Saad F et al. Increased survival with enzalutamide in prostate cancer after chemotherapy. N. Engl. J. Med. 367, 1187-1197 (2012).

46 Beer TM, Armstrong AJ, Rathkopf DE et al. Enzalutamide in metastatic prostate cancer before chemotherapy. N. Engl. J. Med. 371, 424-433 (2014).

47 Smith M, Borre M, Rathenborg P et al. Efficacy and safety of enzalutamide (ENZA) monotherapy in hormone-naive prostate cancer (HNPC). J. Clin. Oncol. 31(Suppl.), Abstract 5001 (2013).

48 Attard G, Belldegrun AS, de Bono JS. Selective blockade of androgenic steroid synthesis by novel lyase inhibitors as a therapeutic strategy for treating metastatic prostate cancer. BJU Int. 96, 1241-1246 (2005).

49 de Bono JS, Logothetis CJ, Molina A et al. Abiraterone and increased survival in metastatic prostate cancer. N. Engl. J. Med. 364, 1995-2005 (2011).

50 Ryan CJ, Smith MR, de Bono JS et al. Abiraterone in metastatic prostate cancer without previous chemotherapy. N. Engl. J. Med. 368, 138-148 (2013).

51 Nelson AW, Tilley WD, Neal DE, Carroll JS. Estrogen receptor beta in prostate cancer: friend or foe? Endocr. Relat. Cancer 21, T219-234 (2014).

52 Grubisha MJ, DeFranco DB. Local endocrine, paracrine and redox signaling networks impact estrogen and androgen crosstalk in the prostate cancer microenvironment. Steroids 78, 538-541 (2013).

53 Verma V, Sharma V, Singh V et al. Designed modulation of sex steroid signaling inhibits telomerase activity and proliferation of human prostate cancer cells. Toxicol. Appl. Pharmacol. 280, 323-334 (2014).

54 Foryst-Ludwig A, Kintscher U. Metabolic impact of estrogen signalling through ERalpha and ERbeta. J. Steroid Biochem. Mol. Biol. 122, 74-81 (2010). 